\title{
Reading Speed Performance based on Interface Design Elements for Web Interfaces
}

\author{
Zuriana Abu Bakar* and Tan Zhiang \\ Universiti Malaysia Terengganu, Malaysia, \\ zuriana@umt.edu.my; uk27773@student.umt.edu.my \\ *Correspondence: zuriana@umt.edu.my
}

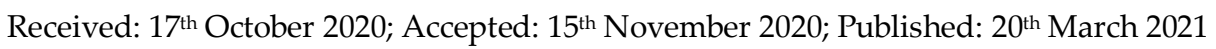

Abstract: The development of technology and internet has contributed to more people viewing on-screen content and an increase the amount of material that can be read directly from a Web-based platform. The transformation from paper-based materials to digital materials on the Web, more or less has affected the readability of the materials in which information presented on the printed and web-based documents is dissimilar. However, only few studies have been carried out on the presentation of information specifically, the readability of the text in web-based platform. Meanwhile, readability is one of the crucial aspect of Web usability and could affect the success of a website. The speed of reading is regarded as a good measure of readability. Therefore, this study aims to measure the readers reading speed for web interfaces. This study followed a quantitative analysis method that used experiments to collect data and involved university students as the test subjects. A Web-based Reading Speed Test System (RSTS) was developed for data collection and analysis purpose. The findings of this study found that the web interface with the combination of blue font color, yellow background color and Arial font type have the highest reading speed. In contrary, web interface that consists of combination black font color, white background color and Arial font type have the lowest reading speed. In addition, the reading speed of male participants was slightly higher than the female participants. To conclude, the results of this study signify that the interface design had a significant impact on the students reading speed for web pages.
\end{abstract}

Keywords: Design elements; Interface design; Reading speed performance; Web interface

\section{Introduction}

Interface design is vital either in a web based system or an offline system. Normally, a system with good interface design is able to let the users understand the complex information and users will have a good experience while interacting with those interfaces. A successful interface design is decided by few factors namely development factors, visibility factors and acceptance factors. Besides, the convenience of internet and the modern technology have increased the number of electronic device users. Most of the things are able to be viewed on the electronic devices. One of them is the text. The reading speed is directly related to the visualization of the text. Therefore, this study aims to investigate the relationship between reading speed and interface design elements, in which the interface design elements are manipulated to analyze the users' reading speed for web interface.

The remaining of this paper is organized as follows. The extensive research background is explained in Section 2. The methodology adopted for this research is described in Section 3 followed by the results and discussion in Section 4. Finally, the conclusion will be in Section 5 . 


\section{Research Background}

The following sub-section provides a detail background of reading speed and interface design elements.

\subsection{Reading Speed}

Previously, there are a number of researches studying the association between the interface design elements and reading speed. The optimization of reading normally depends on reading time and comprehension.

According to Bailey [1], there are five (5) frequently human interactions with computer, which are reading, listening, speaking, keying and handwriting. By using rapid serial visual presentation (RSVP), reading speed can be significantly increased. People with moderate practice can read at 400 words per minute, while people with less than one (1) hour of practice can read easily at 600 to 800 words per minute or faster [1]. On the other hand, Ziefie [2] stated that when people scanning text on paper, usually their reading speed are about 200 words per minute. However, performing an exact same task using a computer screen, they read about 10\% slower at 180 words per minute. From the researches discussed, it has been found that the presentation on the monitor will affect the reading speed either it will speed up or slow down.

\subsection{Reading Speed and Gender}

A few studies have focused on gender differences related with reading skill domain. Lynn \& Mikk [3] has been carried out a study about the sex effect size and variances in reading attainment in recent international studies. They found that the female obtained higher achievement in reading compared to male. Another study by Roivainen [4] investigated gender differences in processing speed and reading and writing skills. This study revealed that females were outperform than males in reading and writing skills.

In a different study, Saint-Aubin, Voyer, \& Roy [5] explored gender differences in the missingletter effect. In an experiment, the equal number of males and females perform a letter detection task. Their reading speed and comprehension were measured. The speed of reading was measured as the number of words read within one (1) minute. As a result, women read much faster than men. Recently, Ghani, Muslim, \& Zakaria [6] published a thorough analysis of the effects of gender and academic achievement on oral reading fluency (ORF) and silent reading fluency (SRF) among Malaysian children in Year 2. However, the result of this study revealed that the gender effect was insignificant. Taken together, from the previous studies discusses in this section, it is shown that females were more outstanding than males in reading skill area.

\subsection{Interface Design Elements}

Interface design elements that applied on the web interfaces of this study are text, font types and font color.

\subsubsection{Text}

Text is a multimedia feature that plays a key role in the dissemination of verbal information for instructional software. [7]. The tendency to obtain information through computers, particularly in an online form, arises successively with the rapid development of computer-based instructions, such as web and courseware [8].

Consequently, the need for text-related study, especially in terms of improving student reading levels, is much more urgent now. The readability of text on computer screens is also important in order to ensure successful contact with the media [9-11].

Therefore, it is so obvious that nowadays people will spend more time on these electronic devices like laptops, smartphones, tablets and so on. These devices are having the same similarity which are equipped with a screen that having different interface designs. In addition, when people search at 
different websites, these websites are also presenting the different interface designs with their own characteristics.

\subsubsection{Font Types}

Normal fonts can be divided into two (2) types, Serif and San Serif [12]. Serif fonts are chosen for long text blocks because they allow the reader to distinguish letters individually [13, 14]. The San Serif or Gothic fonts have no tiny strokes compared to the Serif fonts. San serif was designed and known during the early 20th century [15]. The quick and transparent style of San serif fonts in the early years makes it ideal as a " display font" [14]. The term "display font" is used for fonts intended for use in advertising signs and posters that can be read clearly even over long distances [12, 15].

Normally, people can differentiate between Serif and San Serif. They are easily to be distinguished and people always use them depends on their mood or the format given. But actually the reading speed based on which font types is faster is difficult to be compared since each of them have their own advantages. Thus, due to the commonly used Serif and San Serif family fonts, both fonts were selected to be applied to the stimuli web interfaces in the present study. Times New Roman, Georgia, and Garamond font types represent Serif family font, whilst Arial and Verdana are on behalf San Serif family font.

\subsubsection{Font Color}

Mayr and Brandt [16] stated that when text is written in dark letters on a light background it is easier to read text from computer screens. They explained that text is more readable when luminance

of the overall display is high. In other study, Scharff, Ahumada, and Hill [17] used two (2) black letter intensities on different background colours to test the speed of reading. They found that text on a light yellow background could be read more quickly than text on a light grey or light blue background.

$\mathrm{Wu}$ and Yuan [18] also studied the impact of color on the speed of reading. The foreground or text should be darker in order to increase the reading speed and the background should be brighter. The best results were black text on green background and black text on yellow background [18]. Another research conducted by Ray, Fowler, and Stein, [19] and Stein [20] that children with difficulty reading who were wearing a yellow filter improved accommodation and convergence. Their sensitivity to motion was also diminished and their contrast improved.

Based on previous studies, it can be clearly seen that font color and background color affect the reading speed especially when the contrast of color between the fonts and background is bigger. For example, the color combination such as black and white or black and light yellow will have a higher contrast of color and luminance level than the other color combinations.

In the current study, color of black, blue, grey and red were chose as font color. On the other hand, color of white, blue, yellow and red were selected as background colors. The font color and background color used in this study are illustrated in Table 1.

\section{Research Methodology}

An experimental approach has been adopted in order to examine participants' speed of reading text that presented in the Web-based format. In the following sub-sections, the participants involved in the study, the measures, and procedure are explained.

\subsection{Participants}

There were 64 Universiti Malaysia Terengganu (UMT) undergraduate students were randomly picked as participants to execute the reading speed test in the computer laboratory of Faculty of Ocean Engineering Technology \& Informatics (FTKKI), UMT. The participants were consisted of 39 male participants and 35 female participants. 


\subsection{Materials}

The total number of web interfaces were 16 as shown in Table 1 . With the total 64 participants, each web interface was displayed to four (4) participants without the restriction of render respectively. In other words, one (1) web interface is tested by four (4) participants, thus, 16 interfaces are evaluated by 64 participants.

Table 1. Web interfaces with interface design elements

\begin{tabular}{|c|c|c|c|c|}
\hline No. & Web Interface & Font Color & Background Color & Font Type \\
\hline 1. & itf01 & Black & White & Georgia \\
\hline 2. & itf02 & Black & White & Garamond \\
\hline 3. & itf03 & Black & White & Arial \\
\hline 4. & itf04 & Black & White & Verdana \\
\hline 5. & itf05 & Blue & Yellow & Georgia \\
\hline 6. & itf06 & Blue & Yellow & Garamond \\
\hline 7. & itf07 & Blue & Yellow & Arial \\
\hline 8. & itf08 & Blue & Yellow & Verdana \\
\hline 9 & itf09 & Grey & Red & Georgia \\
\hline 10. & itf10 & Grey & Red & Garamond \\
\hline 11. & itf11 & Grey & Red & Arial \\
\hline 12. & itf12 & Grey & Red & Verdana \\
\hline 13. & itf13 & Red & Blue & Georgia \\
\hline 14. & itf14 & Red & Blue & Garamond \\
\hline 15. & itf15 & Red & Blue & Arial \\
\hline 16. & itf16 & Red & Blue & Verdana \\
\hline
\end{tabular}

\subsection{Procedure}

The experiment was conducted in a controlled environment which was in the FTKKI computer laboratory. The reading speed test took about 15 to 30 minutes.

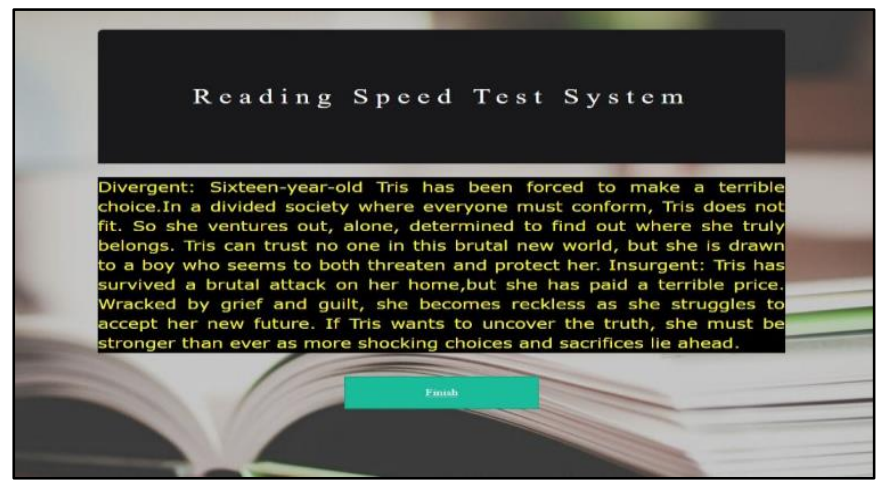

Figure 1. Reading Test Page

The RSTS is a web-based system was used in this experiment to collect and analyse the data in the current study. MySQL server was connected to the FTKKI laboratory. Therefore, the participants in the laboratory could carry out the reading speed test and the local database could record and update all the information obtained. Before the experiment started, the researcher briefed the participants about the RSTS and informed them the purpose of this experiment. Afterwards, the participants used the RSTS during the experiment.

For a starting, participants have to provide their personal information which are matric number, age and gender before starting the reading speed test at the participants' registration page. Then, participant will be redirected to the reading page after finishing registration. Figure 1 shows the reading test page. Here, the participants were required to read the text given. Once participant enters this page, 
the time taken will be counted until the participant click the "Finish" button to end the test. Figure 2 shows reading test result page. This page will be redirected after participant finished reading the text. Participant can check and review the result which are time taken and word per minute.

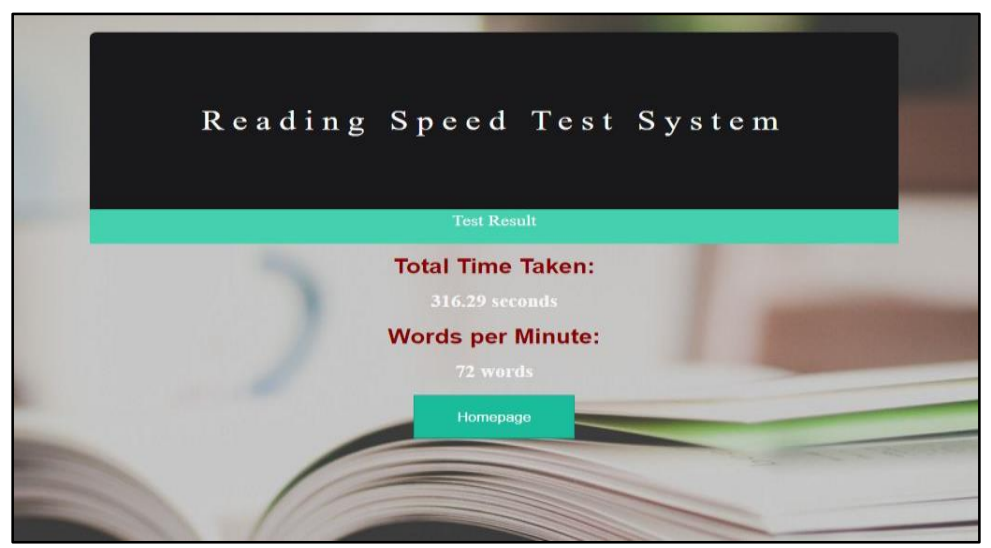

Figure 2. Test Results Page

\section{Results and Discussion}

The results of this study consist of reading speed versus interface design and reading speed versus gender. The results are visualised by column charts.

\subsection{Result of Reading Speed versus Interface Design}

Table 2 shows the results of time taken and word per minute (wpm) for 16 interfaces. It is clearly depicts that interface itf07 had the highest wpm and the shortest/lowest time taken. In contrary, interface itf03 had the lowest wpm and the longest/highest time taken. Refer to Table 1 in subsection 3.2 to obtain the information about interfaces and their design elements.

Table 2. Results of time taken and WPM for each web interface

\begin{tabular}{|c|c|c|c|}
\hline No. & Web Interface & Word per Minute & Time Taken (seconds) \\
\hline 1. & itf01 & 160 & 107.20 \\
\hline 2. & itf02 & 224 & 71.22 \\
\hline 3. & itf03 & 119 & 132.82 \\
\hline 4. & itf04 & 182 & 103.74 \\
\hline 5. & itf05 & 187 & 87.54 \\
\hline 6. & itf06 & 249 & 71.72 \\
\hline 7. & itf07 & 439 & 37.40 \\
\hline 8. & itf08 & 356 & 46.55 \\
\hline 9 & itf09 & 201 & 80.71 \\
\hline 10. & itf10 & 201 & 79.97 \\
\hline 11. & itf11 & 258 & 74.70 \\
\hline 12. & itf12 & 184 & 87.06 \\
\hline 13. & itf13 & 181 & 87.89 \\
\hline 14. & itf14 & 173 & 92.34 \\
\hline 15. & itf15 & 168 & 94.72 \\
\hline 16. & itf16 & 160 & 100.00 \\
\hline
\end{tabular}

As presented in Table 2, it can be seen that the web interface itf07, which consists of blue font color, yellow background color and Arial font type had the highest reading speed, which was $439 \mathrm{wpm}$ in overall 37.40 seconds. In contrast, interface itf03, that comprised of black font color, white background color and Arial font type had the lowest reading speed, which was $119 \mathrm{wpm}$ in overall 132.82 seconds. The results reveal that text-background colour combination had a greater impact on reading speed. 
Blue and yellow combinations contribute to the best performance in reading speed measurement. This is consistent with previous studies, in which the brightest contrast was between blue and yellow, and the pattern across all colour combinations was the higher the luminance contrast, the better the efficiency [21].

Meanwhile, although combination of black on white is the greatest contrast color combination, this combination is the least arousing colour. White is clean and simple [21] and the background colour dominates the appearance of the interface. Consequently, it may make people feel relaxed and calm and brings about low arousal [22]. This emotional respond may influence the reading speed performance because when people in low arousal state, it may slow down their reading speed rate.

Regarding the font type, both interfaces that obtained highest and lowest reading speed had used Arial font type. Thus, it can be suggested that font type give less impact on reading speed. The possible explanation for this outcome is according to McCracken \& Wolfe [23] and Beird [24], a large part of the text content on the Web appears in the Sans Serif typeface and the Arial typeface is the most commonly used font on the Web. Thus, people already get used Arial font type and this is why there is less impact of font type in reading speed test. Figure 3 illustrates the chart of time taken and wpm against interfaces.

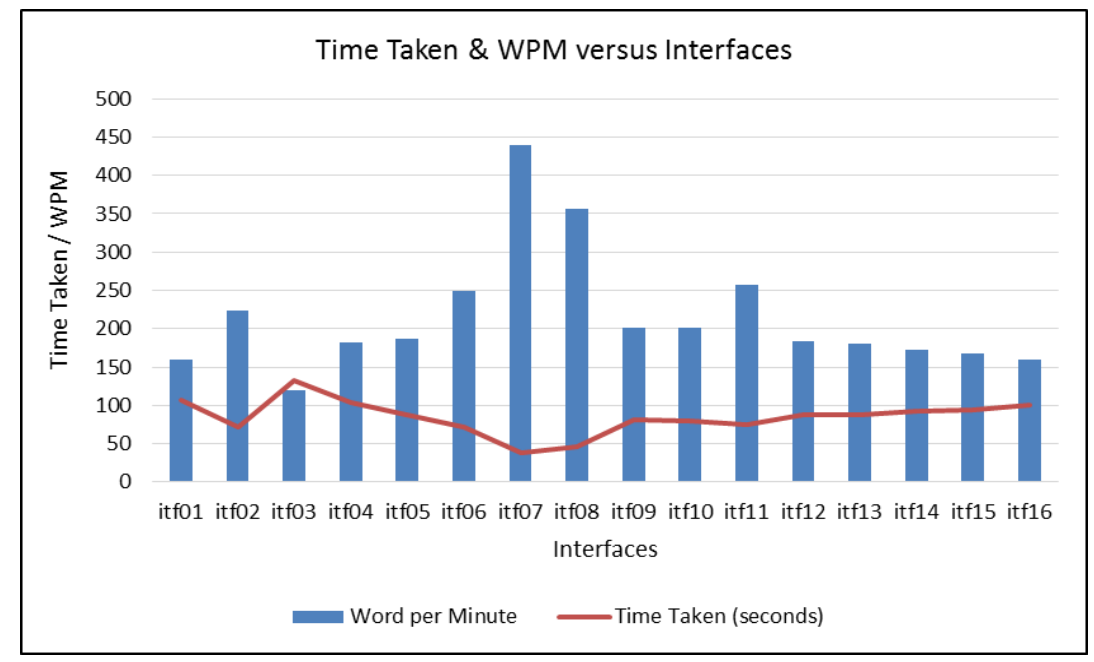

Figure 3. Time taken and WPM versus interfaces

\subsection{Result of Reading Speed and Gender}

Figure 4 illustrates the result of time taken and wpm versus gender. The time taken for male participants was 84 seconds while female participants was 86 seconds in overall. The difference in time taken is only 2 seconds. On the other hand, the wpm for male participants was 224 while female participants was 202. Male participants had a slightly higher wpm compared to female participants.

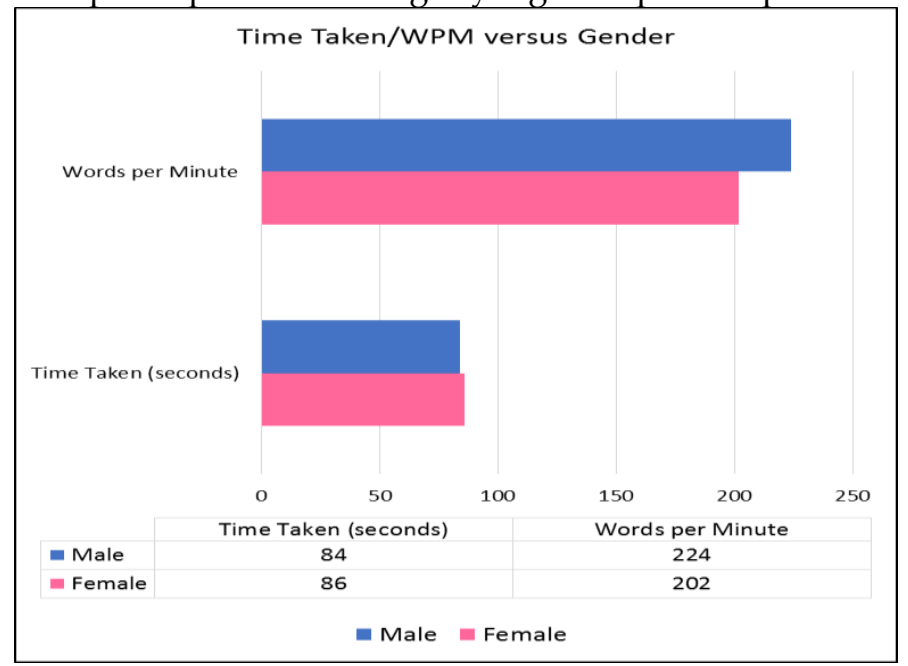

Figure 4. Time taken and WPM versus gender 
In overall, the reading speed is inversely proportional to the time taken for reading through the text. The higher the time taken, the lower the word per minute will be obtained. Both charts clearly showed that the reading speed of male participants was higher than the female participants.

This results are contradict with the several previous studies discussed in subsection 2.2, in which, those three (3) studies found that females were more perform than males in reading skill area [3-5].

This contradict result can be due to the environmental factors that could affect the subjects' reading speed during the experiments such as subjects' posture, distance from the screen and room illumination [25]. Those aspects might influence the participants' eye vision and indirectly influence their reading performance.

\section{Conclusion}

This study had investigated the association between reading speed and interface design elements for web pages. Thus, the results of this study clearly showed that the interface design element that consists of font color, background color and font type contribute a significant impact on the students reading speed for web pages. The combination of blue font color and yellow background color and Arial font type achieved the highest reading speed whilst, black font color, white background color and Arial font type obtained the lowest reading speed. Furthermore, this also found that the males are outperformed than females in reading speed.

In addition, the development of web-based RSTS as a supporting system truly could assist the researchers to conduct reading speed test, data collection, executing data analysis and automatically generating the results. Moreover, RSTS was developed on web-based platform that could be easily accessed by users at anywhere and anytime as long as connected to the internet.

\section{References}

[1] R. W. Bailey, Human Performance Engineering: Designing High Quality Professional User Interfaces for Computer Products, Applications and Systems. United States: Prentice Hall, 1996.

[2] M. Ziefle, "Effects of Display Resolution on Visual Performance" Human Factors: The Journal of the Human Factors and Ergonomics Society, vol. 40, pp. 554-568, 1998.

[3] R. Lynn and J. Mikk, "Sex Differences in Reading Achievement" TRAMES, vol. 13, pp. 3-13, 2009.

[4] E. Roivainen, "Gender differences in processing speed: A review of recent research, "Learning and Individual Differences", vol. 21, pp. 145-149, 2011.

[5] J. Saint-Aubin, D. Voyer, and M. Roy, "Sex differences in the missing-letter effect: A question of reading or visual-spatial skills?", Learning and Individual Differences, vol. 22, pp. 664-672, 2012.

[6] A. A. Ghani, N. H. Muslim, and M. N. Zakaria, "The Effects of Gender and Academic Achievement on Reading Fluency Among Year 2 Malaysian School Children", International Journal of Pediatric Otorhinolaryngology, vol. $132,2020$.

[7] A. Z. M. Ali, R. Wahid, K. Samsudin, and M. Z. Idris, "Reading on the Computer Screen: Does Font Type has Effects on Web Text Readability?", International Education Studies, vol. 6, pp. 26-35, 2013.

[8] T. G. Ferrari and C. Short, "Legibility and Readability on the World Wide Web", University of BuenosAires, Argentina, Buenos Aires, Argentina2002.

[9] Y. Erdogan and S. Bayram, "The Effects of Gender and Visual Disability Ffactors on The Legibility of Web Pages", Journal of Literacy \& Technology, vol. 8, pp. 1-20, 2007.

[10] J. Nielsen, Designing Web usability: The practice of simplicity. California, USA: New Riders Publishing, 2000.

[11] Y. Erdogan, "Legibility of Websites Which are Designed for Instructional Purposes", World Applied Sciences Journal, vol. 3, pp. 73-78, 2008.

[12] G. Ambrose and P. Harris, The Fundamentals of Typography. Switzerland: AVA Publishing SA, 2006.

[13] D. A. Amdur, Typographic Design in The Digital Studio: Design concepts. Clifton Park, New York: Thomas Delmar Learning, 2007.

[14] M. Bryan, Digital Typography Sourcebook. Canada: John Wiley \& Sons Inc, 1996.

[15] T. R. Deer, Exploring Typography. Clifton Park, New York: Thomson Delmar Learning, 2006.

[16] A. Buchner, S. Mayr, and M. Brandt, "The Advantage of Positive Text-Background Polarity is Due to High Display Luminance", Ergonomics, vol. 52, pp. 882-886, 2009.

[17] L. F. V. Scharff, A. Ahumada, and A. Hill, "Discriminability Measures for Predicting Readability of Text on Textured Backgrounds", Optic Express, vol. 6, pp. 81-91, 2000. 
[18] J.-H. Wu and Y. Yuan, "Improving Searching and Reading Performance: The Effect of Highlighting and Text Color Coding", Information Management, vol. 40, pp. 617-637, 2003.

[19] N. J. Ray, S. Fowler, and J. F. Stein, "Yellow Filters Can Improve Magnocellular Function: Motion Sensitivity, Convergence, Accommodation, and Reading", New Yorl Academy of Sciences, pp. 283-293, 2005.

[20] J. Stein, "Evaluation of An Exercise based Ttreatment for Children with Reading Difficulties", Dyslexia: An International Jpurnal of Research and Practice, vol. 9, pp. 124-126, 2003.

[21] N. Kaya and H. H. Epps, "Relationship Between Color And Emotion: A study Of College Students", College Student Journal, vol. 38, pp. 396-405, 2004.

[22] Z. A. Bakar, "A Study to Investigate the Impact of Visual Interface Design on User Experience in Web-based Learning Application", PhD, School of Information Technology and Electrical Engineering, The University of Queensland, Brisbane, Australia, 2014.

[23] D. D. McCracken and R. J. Wolfe, User-centered website development: A human-computer interaction approach. New Jersey: Pearson Prentice Hall, 2004.

[24] J. Beaird, The Principles of Beautiful Web Design. Collingwood, Victoria, Australia: Site Point Pty. Ltd, 2007.

[25] P. Muter and P. Maurutto, "Reading and Skimming from Computer Screens and Books: The Paperless Office Revisited?", Behaviour and Information Technology, vol. 10, pp. 257-266, 1991.

(C) 2021 by the author(s). Published by Annals of Emerging Technologies in Computing (AETiC), under the terms and conditions of the Creative Commons Attribution (CC BY) license which can be accessed at http://creativecommons.org/licenses/by/4.0. 